\title{
FORMAÇÃO DE PROFESSORES DA EDUCAÇÃOO BÁSICA: ANÁLISE DOS PROCESSOS FORMATIVOS
}

\author{
Simone Regina Manosso Cartaxo (UEPG)* \\ https://orcid.org/0000-0002-8670-6324 \\ Marilia Marques Mira (UP)** \\ https://orcid.org/0000-0003-0173-6055 \\ Rosangela Gasparim (UP)*** \\ https://orcid.org/0000-0003-2567-5162
}

\section{RESUMO}

O texto aborda a formação continuada de professores da educação básica na Rede Municipal de Ensino de Curitiba e tem como objetivo caracterizar os diferentes movimentos formativos, a fim de identificar a existência de processos de organização coletiva dos/com professores no ensino fundamental a partir das próprias práticas produzidas no contexto de trabalho da escola. Apoia-se na epistemologia da teoria como expressão da prática para realizar uma revisão sistemática que toma como referência dados de pesquisas realizadas sobre a formação continuada nessa rede de ensino. Os resultados indicam que, no contexto dos movimentos formativos analisados, há alguns aspectos que podem ser considerados como elementos determinantes na direção de fragilizar a organização coletiva dos docentes: a ausência de um projeto de formação que não se limite ao período de uma gestão no governo, a influência das avaliações em larga escala e a perspectiva da distribuição do conhecimento.

Palavras-chave: Projeto de formação continuada. Prática pedagógica. Formação de professores.

\section{ABSTRACT \\ EDUCATION TEACHER TRAINING: ANALYSIS OF TRAINING PROCESSES}

The text addresses the continuing education of teachers of basic education in

\footnotetext{
Doutora em Educação pela Pontifícia Universidade Católica do Paraná (PUC/PR). Professora do Departamento de Pedagogia e do Programa de Pós-Graduação em Educação da Universidade Estadual de Ponta Grossa (UEPG). Membro do Grupo de Estudo e Pesquisa Didática e Formação Docente (GEPEDIDO) e da Rede Interinstitucional de Pesquisadores em Formação de Professores (RIPEFOR). E-mail: simonemcartaxo@hotmail.com

** Doutora em Educação pela Pontifícia Universidade Católica do Paraná (PUC/PR). Professora do Curso de Pedagogia da Universidade Positivo (UP). Membro do Grupo de Pesquisa Práxis Educativa: dimensões e processos (PUC/PR), da Rede Interinstitucional de Pesquisadores em Formação de Professores (RIPEFOR) e da Red de Inducción a la Docencia. E-mail: marilia.mira@up.edu.br

*** Mestre em Educação pela Pontifícia Universidade Católica do Paraná (PUC/PR). Pedagoga na Rede Municipal de Ensino de Curitiba. E-mal: rosangelagasparim@gmail.com
} 
the Curitiba Municipal Education Network and aims to characterize the different formative movements, in order to identify the existence of processes of collective organization of / with teachers in elementary school from their own. practices produced in the school work context. It relies on the epistemology of theory as an expression of practice to conduct a systematic review that draws on data from research on continuing education in this education network. The results indicate that, in the context of the formative movements analyzed, there are some aspects that can be considered as determining elements in the direction of weakening the collective organization of teachers: the absence of a training project that is not limited to the period of government administration, the influence of large scale assessments and the perspective of knowledge distribution.

Keywords: Continuing education project. Pedagogical practice. Teacher training.

\section{RESUMEN}

\section{FORMACIÓN DE PROFESORES DE EDUCACIÓN: ANÁLISIS DE LOS PROCESOS DE FORMACIÓN}

El texto aborda la educación continua de los docentes de educación básica en la Red de Educación Municipal de Curitiba y tiene como objetivo caracterizar los diferentes movimientos formativos, con el fin de identificar la existencia de procesos de organización colectiva de / con docentes en la escuela primaria desde los suyos. prácticas producidas en el contexto laboral escolar. Se basa en la epistemología de la teoría como expresión de la práctica para realizar una revisión sistemática que se basa en datos de investigaciones sobre educación continua en esta red educativa. Los resultados indican que, en el contexto de los movimientos formativos analizados, hay algunos aspectos que pueden considerarse como elementos determinantes para debilitar la organización colectiva de los docentes: la ausencia de un proyecto de capacitación que no se limite al período de administración gubernamental. , la influencia de las evaluaciones a gran escala y la perspectiva de la distribución del conocimiento. Palabras clave: Proyecto de educación continua. Práctica pedagógica. Formación de profesores.

\section{Introdução}

0 texto aborda a formação continuada de professores da educação básica na Rede Municipal de Ensino (RME) de Curitiba, com o objetivo de caracterizar os diferentes movimentos formativos no período de 1963 a 2016, a fim de identificar a existência de processos de organização coletiva dos/com professores no ensino fundamental, a partir das próprias práticas produzidas no contexto de trabalho da escola.

Compreendemos que a configuração da formação continuada, como discutida por Diniz
-Pereira (2019, p. 67), tem se caracterizado por "ações isoladas, pontuais e de caráter eventual", tratando-se de uma formação descontinuada muito mais que contínua, com ofertas de várias modalidades "em que os temas e os conteúdos ali tratados não necessariamente refletem as necessidades formativas dos docentes". Neste sentido, Franco (2019, p. 96), em defesa de uma formação "de/para/com" os professores, assume como princípio para a formação "a participação voluntária dos docentes, partici- 
pação desejada, permitida e talvez solicitada, sob forma de adesão a um projeto de formação".

Para Imbernón (2002, p. 49), trata-se de abandonar um conceito obsoleto de formação no sentido de "atualização científica, didática e psicopedagógica do professor, mas pensar na formação do professor que possibilite descobrir, organizar, fundamentar, revisar e construir a teoria". Esse conceito pressupõe que o profissional de educação é construtor de conhecimentos pedagógicos, tanto no plano individual como no plano coletivo, ou seja, "o professor é sujeito e não objeto de formação" (IMBERNÓN, 2002, p. 81).

Neste sentido, assumimos como princípio organizador - para caracterizar os movimentos formativos e identificar a existência de processos de organização coletiva dos/com professores no ensino fundamental - o eixo epistemológico da teoria como expressão da prática. 0 sistema teórico que fundamenta este eixo sustenta-se na compreensão da experiência de um determinado tipo de prática pedagógica, das análises de outras práticas semelhantes e da tentativa de conceber aspirações mais profundas da prática social dos professores trabalhadores. Assim, se pretendemos uma prática pedagógica articulada aos interesses dos trabalhadores, aprender com eles como se gera esta pedagogia é fundamental.

É um processo metodológico que fundamenta-se na proposta de sistematização coletiva do conhecimento (MARTINS, 1996), sendo desenvolvido em momentos fundamentais e intimamente relacionados e que contemplam: a caracterização e problematização da prática pedagógica dos professores; a explicação da prática mediatizada por um referencial teórico; a compreensão da prática no nível da totalidade; e a elaboração de propostas para intervenção na prática.

Várias pesquisas têm se dedicado à análise da formação continuada dos professores da educação básica, tendo em vista o crescimento das redes de ensino e as demandas que se originam para formar professores e, no caso da RME de Curitiba, identificamos pesquisas como: Dalla-Bona (1990), Cartaxo (2009), Morais, (2009), Vieira (2010), Mira e Gasparim (2017), Mira (2018), Gasparim (2019).

Dalla-Bona (1990) examinou o treinamento e o aperfeiçoamento de professores da RME de Curitiba desde a sua implantação, em 1963, até 1988. Desenvolveu análise crítica sobre as propostas educacionais do município e implicações para a formação dos professores considerando o contexto brasileiro de educação.

Cartaxo (2009) analisou a formação continuada de professores alfabetizadores no período entre 1963 e 2008, a partir da identificação de como se caracterizaram os momentos da formação continuada dos professores e análise dos processos de formação que se constituíram na RME.

Vieira (2010) pesquisou as relações entre as políticas públicas adotadas pela RME de Curitiba no período compreendido entre 1963 e 1996 e a formação continuada de professores. Destacamos, dentre seus objetivos de pesquisa, a investigação sobre o papel destinado à formação continuada dos professores em cada um dos períodos estudados e a maneira como essa formação foi realizada.

Morais (2009) investigou como o processo de formação continuada do professor, utilizado como estratégia de formação profissional, foi se caracterizando na RME de Curitiba no período entre 1980 e 2007 para os professores que atuam no Ensino Fundamental, enfocando as tendências que fundamentam a capacitação docente, analisando-as sob a perspectiva do trabalho como práxis humana.

Mira e Gasparim (2017) analisaram o Programa de Formação Integrada (PROFI), desenvolvido em 2016 na RME de Curitiba, inferindo seus limites e contribuições na perspectiva do desenvolvimento profissional docente. A pesquisa de campo envolveu a análise do documento oficial do Programa e a realização de entrevistas com diferentes profissionais que participaram desse processo (professores, 
pedagogos, formadores, gerentes da secretaria de educação), além de depoimentos escritos de um grupo de profissionais participantes, relacionados à avaliação do trabalho, ao final do Programa.

Mira (2018), em pesquisa sobre a inserção de professores na RME de Curitiba, analisou - entre outros aspectos - os processos de formação continuada voltados aos professores ingressantes, buscando inferir contribuições e limites dos processos formativos vivenciados no período da inserção desses profissionais na Rede.

Gasparim (2019) investigou, por meio de estudo de caso, o PROFI, analisando as contribuições teórico-práticas desta formação para a prática de um grupo de 57 professores. A pesquisa teve como campo de investigação 13 escolas municipais, com dados recolhidos por meio de questionários e entrevistas semiestruturadas, além de análise documental.

Essas pesquisas e alguns documentos e memórias da RME serviram de referência para caracterizar os diferentes movimentos formativos, a fim de identificar processos de organização coletiva dos/com professores no ensino fundamental. A organização se apresenta em períodos vinculados ao contexto nacional da educação destacados por Martins (1998).

A organização dos períodos cumpre um papel didático e não pretende, com isso, demarcar momentos históricos. A delimitação de ideias preponderantes para cada período não tira a possibilidade de encontrá-las em outro, pois considera-se que o tempo de produção de ideias segue um movimento próprio e não estanque.

0 primeiro período inicia-se em 1963 , ano em que é construída a primeira escola municipal e têm início as atividades de formação de professores no interior da própria escola. São iniciativas isoladas e voluntárias para atender às necessidades imediatas.

O segundo período compreende a década de 1970, quando se observa uma padronização da formação de professores por meio de cursos de treinamento em métodos, principalmente na área de alfabetização.

O terceiro período compreende a década de 1980, no qual começa a ser gestado um movimento de mudança decorrente do contexto nacional pós-ditadura. É nesse momento que se evidencia a dimensão política do ato pedagógico.

O quarto período compreende toda a década de 1990 e tem como foco a organização do trabalho na escola; os olhares voltam-se para as questões da prática e a problemática do ensino recai sobre o processo de produção e sistematização coletiva do conhecimento, passando o aluno a ser visto como sujeito portador de uma prática social e com interesses próprios.

O quinto período, a partir de 2000 , é caracterizado pela intensificação da aprendizagem no sentido de "aprender a aprender", em que as habilidades específicas são conceituadas como competências previamente definidas nos programas de aprendizagem.

A seguir, é apresentado o detalhamento de cada período contemplando informações do contexto da educação da RME de Curitiba e destaques sobre a formação de professores. A partir dessa contextualização inicial para caracterizar os diferentes movimentos formativos, buscar-se-á identificar a existência de processos de organização coletiva dos/com professores no ensino fundamental, considerando as próprias práticas produzidas no contexto de trabalho da escola.

\section{0 início da Rede Municipal de Ensino de Curitiba}

O movimento de criação da RME começa na década de 1950, embora sem o caráter de uma rede municipal, pois as escolas estavam subordinadas ao Estado, no contexto em que a recém-restaurada democracia brasileira conhecia a curta primavera do pós-guerra, enfrentando o conturbado mandato de Getúlio Vargas (COSTA, 2007). 
Os registros que marcam a trajetória inicial da educação no município são localizados no documento que registra as memórias da Rede Municipal de Ensino de Curitiba (CURITIBA, 2007), trabalho desenvolvido por uma comissão envolvendo professores e pesquisadores que se apoiaram em uma densa pesquisa documental e depoimentos de pessoas que fizeram parte dessa história.

Consta que em 1955 foi criada a Seção de Educação e Cultura no Departamento de Educação, Cultura e Turismo e, como resultado, houve o aumento do número de escolas públicas da cidade subordinadas ao Estado. Em 1959, a Seção torna-se Serviço de Educação e Cultura, e em 1963 é criada a Diretoria de Educação e Recreação Pública como parte do Departamento de Educação, Saúde e Recreação. Até esse momento, as ações da Diretoria e do Departamento não tinham um caráter sistemático, e somente com a criação do Centro Experimental Papa João XXIII, em 1963, é que o ensino público municipal começa a tomar forma (CURITIBA, 2007).

Nesse período, os professores eram providos pelo Estado, já que ainda era responsabilidade dele atender o setor da educação. Aos poucos é que o município foi criando suas escolas e começando a contratar seus professores. Em 1963, foi criada a carreira de professor normalista da RME, porém ainda sem concurso público.

Data de 1963 uma iniciativa isolada de formação continuada promovida pela administração municipal, registro de que a primeira professora que atendeu o jardim de infância no Centro Experimental Papa João XXIII foi "dispensada no ano seguinte para fazer um curso de especialização no atendimento de jardins de infância, visando melhorar seu desempenho nessa área" (COSTA, 2007, p. 12).

Em 1965, o Departamento de Educação, Saúde e Recreação passou a denominar-se Departamento do Bem-Estar Social, e a Diretoria de Educação continua a existir, porém sem ter ainda uma estrutura sólida.
No ano seguinte, 1966, mais escolas foram construídas, entre elas o Grupo Escolar Nossa Senhora da Luz, chamado de "Grupão". Construído no primeiro conjunto habitacional da Cohab-CT, foi inaugurado com a presença do Presidente da República Marechal Humberto de Alencar Castelo Branco. Essa escola constituiu um marco para a educação em Curitiba pelos desafios ali presentes: muitas turmas e professores novos, uma comunidade nova, um trabalho a ser construído (CURITIBA, 2007).

A Lei no 2.827, de julho de 1966, criou a Semana Municipal de Educação e Saúde, primeira iniciativa registrada com o objetivo de discussão coletiva das questões relativas à educação e saúde. Dentre os temas abordados nessa formação constaram: educação rural, educação juvenil, educação integral, artes industriais, educação para a cidadania, delinquência infanto-juvenil (VIEIRA, 2010).

No período entre 1967 e 1969 foi organizado concurso para a admissão de um quadro permanente de professores, e o decreto no 259, de 12 de março de 1969, atribui à Diretoria de Educação e Departamento do Bem-Estar Social responsabilidade sobre cursos de aperfeiçoamento e especialização aos docentes (VIEIRA, 2010).

Vieira (2010, p. 134), em sua análise, destaca:

Assim, ao mesmo tempo em que o Município buscava ampliar seus programas sociais, percebia-se ser necessário atuar na capacitação docente. A valorização do magistério se apresentava, portanto, como uma das variáveis mais importantes a ser manipulada, objetivando a elevação dos padrões de rendimento da escola. A partir daí, passaram a ser adotadas fórmulas que estimulassem o professorado a se aperfeiçoar e a renovar periodicamente seus conhecimentos considerando-se que os resultados decorrentes contribuiriam para a superação da qualidade do ensino local.

As justificativas sobre a necessidade dos cursos de aperfeiçoamento de professores pautam-se em carências identificadas na sua formação inicial, compreendendo que o curso 
Normal, exigência para a docência à época, não capacitava a professora para o bom desempenho de suas funções. Ainda, a não qualificação do corpo docente tornava-se obstáculo para um melhor rendimento do sistema. A partir de 1969, o Departamento do Bem-Estar Social passou à realização de encontros pedagógicos regulamentados com o objetivo de aprimorar o corpo docente (VIEIRA, 2010).

A criação da RME de Curitiba deu-se em um contexto de crescimento da cidade e ampliação das áreas urbanas periféricas, com demandas para expandir a rede escolar nas áreas mais carentes junto com outros serviços sociais.

É interessante registrar, ainda, para esse período inicial da constituição da RME, os documentos que indicam a realização da $2^{\mathrm{a}} \mathrm{e}$ da 3a Convenção Anual de Educação e Saúde, promovidas pela Federação das Associações de Pais e Mestres do Estado do Paraná, em parceria com a Prefeitura Municipal de Curitiba, realizadas nos anos de 1967 e 1968.

Enquanto não havia uma divisão responsável pelo aperfeiçoamento dos professores, cabia à unidade escolar apresentar à Diretoria de Educação, responsável pelos cursos, listas dos professores para os cursos necessários à sua atualização pedagógica. Dado o pequeno número de escolas à época, era possível requerer cursos diretamente na escola (DALLA-BONA, 1990). Além disso, professores se organizavam no interior das escolas para realizar um planejamento semanal aos sábados, além de seu horário de trabalho (CARTAXO, 2009).

\section{Década de 1970: o auge do tecnicismo}

Em 1971, a Seção de Orientação Pedagógica ficou responsável pelo planejamento anual das escolas, pesquisas de campo sobre deficiências do processo de ensino e aprendizagem e organização de grupos de estudos sobre temas relevantes da área pedagógica. Na década de 1970, a RME estava no processo de implantação da Reforma de Lei no 5.692/71 (BRASIL, 1971) e, em 1972, a Diretoria de Educação organizou vários encontros técnico-administrativos e a Seção Pedagógica desenvolveu projetos específicos para orientar e supervisionar pedagogicamente as escolas municipais, dentre eles a Semana de Orientação Pedagógica, destinada à preparação de currículos. Nesse sentido, a organização do trabalho pedagógico pautava-se na predeterminação do trabalho do professor por instâncias superiores. A reforma trazia novidades e era necessário dominar um novo vocabulário para colocar em prática o que se determinava (VIEIRA, 2010).

No contexto da nova lei, os municípios passaram por uma reestruturação, uma vez que passaram a arcar gradativamente com o ônus da educação, envolvendo a construção de prédios, recrutamento de profissionais e manutenção e treinamento desse pessoal. Os escassos recursos municipais agravaram as dificuldades de atender a todas as demandas do ensino.

Ao final do ano de 1973, os professores foram consultados sobre os temas de interesse para a realização de futuros cursos, sendo mencionados temas como: criatividade em redação, planejamento, alfabetização, aplicação de matemática moderna, educação sanitária, psicologia infantil, ciências físicas e biológicas. (VIEIRA, 2010).

Em 1977, as escolas municipais recebem o primeiro currículo que, em sua apresentação, indica a necessidade de aprimorar as condições de funcionamento da RME "como um todo harmônico e eficiente”, sendo necessário "controlar o processo educacional e capacitá-lo para funcionar como um sistema" (DALLA-BONA, 1990 , p. 72), e para isso foram aplicados testes unificados. Na lógica da concepção tecnicista, o treinamento se fortalece, os especialistas são valorizados como controladores do processo, há definição racional de objetivos instrucionais a serem alcançados e os professores executam as ações na escola.

Nesse período, identifica-se que o foco está centrado nos treinamentos em técnicas 
com base em diferentes propostas e métodos que vinham sendo trabalhados com os professores na década anterior. Como exemplos de outros cursos, podemos encontrar: treinamento sobre teatro na educação; treinamento em artes industriais; atualização em técnicas agrícolas; novas técnicas do ensino da Matemática.

Essa abordagem refere-se à concepção pedagógica tecnicista decorrente da reforma do ensino pela Lei n. ${ }^{\circ}$ 5692/71. É uma visão de homem como um ser isolado da sociedade, passivo e acrítico, incapaz de realizar a práxis. A sociedade é concebida de forma estática, homogênea e vazia de valores antagônicos e de luta de classes.

Sendo assim, pode-se pressupor que centralizar a discussão no melhor método de ensino é o mesmo que buscar a formação de classes homogêneas para facilitar o processo de ensino, desconsiderando outros fatores determinantes.

Essa concepção tem como elemento principal a organização racional dos meios com a operacionalização dos objetivos, a mecanização do processo e o parcelamento do trabalho pedagógico, tendo em vista buscar a eficiência minimizando as interferências subjetivas. A padronização do ensino dá-se por meio de um planejamento formulado previamente, que determina ao professor e ao aluno o que, quando e como fazer.

Nessa visão, o papel da escola passa a ser de "repetidora dos programas de treinamento", como analisa Veiga (1995, p. 21). Nesse momento, não se dá espaço para a escola assumir a gestão de seus processos e não se valoriza os conhecimentos que os professores têm de sua prática pedagógica.

O processo de formação de professores, na década de 1970, é marcado pelo treinamento. A Portaria no 09, de 17 de julho de 1979, cria a Divisão de Treinamento Pedagógico com a função de atender os recursos humanos do Município e estabelecer "uma política global e funcional para o desenvolvimento de recursos humanos, em articulação com o Sistema Estad- ual de Ensino e outras Instituições" (CURITIBA, 1979 apud VIEIRA, 2010, p. 151).

\section{Década de 1980: do tecnicismo à Escola Aberta}

O período inicial da década de 1980 foi marcado nacionalmente pela liberdade política e por mudanças radicais. Nos governos estadual e municipal, assumem respectivamente governador e prefeito do Partido do Movimento Democrático Brasileiro (PMDB), comprometidos com uma proposta de democracia e participação coletiva. 0 governo municipal assumiu compromisso com os interesses da maioria da população e rompeu com os interesses das classes privilegiadas. Assim, na área educacional, a gestão municipal adota uma "política de superação da postura tecnicista por meio de uma ação crítica e democrática por parte dos professores", estimulando a "autonomia da escola e participação da comunidade no processo educativo e um planejamento dinâmico com vistas à promoção da democracia" (VIEIRA, 2010, p. 285).

Para Dalla-Bona (1990), nesse período, a estrutura e as propostas educacionais para o aperfeiçoamento dos professores no contexto da educação brasileira parte da ideia de que o professor, por muito tempo, foi treinado para o trabalho docente. 0 termo "treinamento", no contexto histórico, absorve a concepção de educação na lógica empresarial e desenvolve-se a serviço do modo de produção capitalista, buscando habilitar o professor para desenvolver apenas parte do trabalho e, nesse contexto, quem pensa não é quem executa. 0 treinamento, na forma de adestramento, contraditoriamente, desenvolve insatisfação no trabalho e, dialeticamente, leva a rupturas. Essa autora afirma que "iniciou-se concretamente na Rede Municipal de Ensino de Curitiba, a partir de 1983, a superação do treinamento e a ruptura com as concepções educacionais que o justificavam" (DALLA-BONA, 1990, p. viii), sendo o ano de 1986 consi- 
derado marco para iniciar o aperfeiçoamento de professores, fundamentado em concepção educacional comprometida com a maioria da população. Justifica que a responsabilidade do professor no autoaperfeiçoamento "é algo que se viabiliza pela vontade política dos dirigentes" com "políticas pedagógicas que viabilizem o resgate da competência profissional (técnica e política) do professor" (DALLA-BONA, 1990, p. ix).

Nesse contexto, além dos cursos de treinamento até então priorizados, é possível perceber um certo movimento nas propostas que tratam de questões mais amplas. As palavras "treinamentos" e "técnicas" começam a tomar menos espaço e passam a ser usadas palavras como "seminário", "encontro", "grupo de estudo" (CARTAXO, 2009).

Em 1983, é realizado o I Simpósio Educacional do Departamento de Educação, com a participação de técnicos das Secretarias Estaduais de Educação do Paraná e de Minas Gerais, além dos integrantes do Departamento de Educação. Com o apoio de materiais como as Diretrizes Educacionais para o Plano de Governo Municipal, o Plano de Ação do Governo Municipal e as Diretrizes da Diretoria Geral de Educação do Departamento de Educação, foi elaborado um documento com caráter de proposta: "Política de Educação para uma Escola Aberta, 1983-1986" (CURITIBA, 1984). Essa proposta foi apresentada aos diretores eleitos e coordenadores administrativos para que colhessem críticas e sugestões dos professores e funcionários das escolas. Durante o primeiro semestre de 1984, equipes do Departamento de Educação foram até as escolas para ouvir os professores e proceder à elaboração do documento final.

0 documento referente à Escola Aberta é apresentado contendo os preceitos constitucionais, os fins da educação, os objetivos do ensino de $1^{\circ}$ e $2^{\circ}$ graus, os conceitos e princípios norteadores da "Educação para uma Escola Aberta", e as diretrizes do Departamento de Educação. Nessas diretrizes encontram-se as diretrizes gerais e as estratégias para a Ação Educacional.

O conceito de Educação para uma Escola Aberta encontra-se no documento assim detalhado:

Entendemos "Escola Aberta" como aquela que oportuniza aos membros da comunidade transmitir suas experiências numa relação de troca. É aquela que através da prática social, do conteúdo organizado, do pensamento coletivo, de um trabalho conjunto, do confronto das relações sociais, promove a articulação dos universos sociais, respeitando o contexto cultural do aluno e a expressão do seu conhecimento, ao mesmo tempo que propicia acesso à cultura elaborada, tendo como fundamental não a substituição de uma cultura pela outra, mas a complementação, o enriquecimento mútuo, ou seja, a troca do saber. Uma Escola Aberta é, portanto, aquela vinculada aos interesses das camadas populares, é ela que transporta as aspirações e necessidades da população para a ação pedagógica e que assume o compromisso não só do acesso, mas da permanência da criança na escola. (CURITIBA, 1984 apud CARTAXO, 2009, p. 84-85).

É nesse contexto de abertura, de participação coletiva das camadas populares que acontece uma mudança significativa no conteúdo dos cursos ofertados aos professores a partir de 1986 (CARTAXO, 2009).

A mudança nos conteúdos e na forma dos cursos vem sendo gestada durante os anos anteriores e começa a mostrar sua cara somente agora. 0 contexto político que se vivenciava, segundo Martins (1998), repercute no interior das escolas e os professores reclamam a participação, caracterizando um momento eminentemente político. A programação do III Seminário Municipal de Educação, realizado em 1984, anuncia os temas e os palestrantes como: "O significado da apropriação do saber pelas camadas populares" - Professora Acácia Küenzer (UFPR); "A escola e a comunidade" - Professor Miguel Arroyo (MG); "Competência Técnica e Competência Política" - Professor Neidson Rodrigues (MG). Participaram do evento cerca de 3.000 professores de $1^{\text {o }}$ grau "para debater os problemas, deficiências da escola e suas relações 
com a comunidade; discutir as diretrizes para uma política educacional de alfabetização, e situar o papel e a participação do corpo docente nesse processo de mudança" (JORNAL ESCOLA ABERTA apud CARTAXO, 2009, p. 86).

Nesse período, é realizada, na forma de Semana Móvel, uma semana inteira dedicada à formação dos professores e Seminários Municipais de Educação envolvendo todos os professores. O Departamento de Educação ofertava, também, assessoramento direto nas escolas por meio de visitas visando atender as necessidades dos docentes.

Em 1985 é aprovado o Estatuto do Magistério Municipal de Curitiba (Lei no 6.561/85), com destaque para a valorização do professor a partir da promoção por merecimento e pela participação em cursos de aperfeiçoamento. Decorrente desta lei, a oferta de cursos pelo Departamento de Educação é ampliada significativamente e o professor passa a ter $20 \%$ da sua carga horária de trabalho destinada ao seu aperfeiçoamento (MORAIS, 2009).

Em 1986, o Departamento de Educação é transformado em Secretaria Municipal de Educação (SME). A Divisão de Treinamento passa a se chamar Divisão de Aperfeiçoamento Profissional, mudança fundamentada na necessidade de repensar a sua finalidade frente à Proposta Político-Pedagógica para o Município (DALLA-BONA, 1990) e com ação definida para dar sustentação para que todos os envolvidos no processo educacional da RME pudessem discutir, participar e refletir sobre ela. As discussões de pano de fundo traziam em seu bojo a concepção histórico-crítica, que passou a ser focada nas áreas do conhecimento e no Currículo Básico elaborado em 1988.

Os cursos assumem a responsabilidade de buscar unidade entre teoria e prática para possibilitar ao professor compreender os princípios teóricos e metodológicos numa visão de totalidade do trabalho. Dalla-Bona (1990) destaca as queixas dos professores a respeito de formações teóricas sem operacionalização na prática da sala de aula e a ação da
SME, pautada na ação coletiva, ofertar cursos fundamentados na práxis, sendo o professor o articulador, elemento fundamental no processo e responsável pela articulação da proposta político-pedagógica do município. Essa concepção rompe com o enfoque controlador dos gestores tão presentes na década anterior.

As formações continuam com a oferta de Semanas Móveis e Seminários, mas foi implantado, como estratégia diferencial de aperfeiçoamento, o assessoramento realizado com pequenos grupos de escolas. Para Dalla-Bona (1990), o assessoramento assume uma forma diferente do que vinha sendo feito: trabalho com pequenos grupos a partir de seus interesses reais; cursos quinzenais possibilitando ao professor reformulação da prática; trocas de experiências; estruturados a partir de várias áreas do conhecimento; locais centrais e de fácil acesso; continuidade dos cursos com cada grupo para aprofundamento dos conteúdos.

Intensificam-se as ações voltadas à formação continuada do professor, com implantação de atendimento setorial permitindo a atuação direta da Secretaria junto às escolas e ao professor, a formação de grupos de estudos, intercâmbio de experiências entre instituições educacionais (VIEIRA, 2010).

Esse contexto é compreendido a partir de Martins (1998), que o caracterizou tendo como critérios as questões recorrentes na prática dos professores e sua expressão teórica nas reflexões presentes nas universidades e demais produções científicas. Segundo essa autora, esse momento traz a dimensão política do ato pedagógico e é marcado por intensa participação social.

\section{Década de 1990 - as organizações coletivas de trabalho}

A década de 1990, segundo Martins (1998), é caracterizada pelas organizações coletivas no interior das escolas e pela ênfase nas questões da prática. 0 professor reclama mais espaço 
para as discussões e, como consequência disso, os cursos que tratavam do tema "Currículo Básico" e do "fazer pedagógico" são realizados dentro das próprias escolas, sendo que cada escola trabalhava de acordo com suas especificidades (CARTAXO, 2009).

Os temas para a formação de professores indicam uma reorganização do trabalho pedagógico no interior das escolas para resolver situações emergentes da educação. Entre os temas, encontram-se: classes de aceleração de estudos; repensando o dia a dia no Centro de Educação Integral; organização da escola em ciclos de aprendizagem.

Em 1988, foi concluída a produção do Currículo Básico depois de longo percurso envolvendo escola, comunidade, corpo técnico da Secretaria, universidade. Essa produção foi desencadeada a partir de 1983, com a Política de Educação para uma Escola Aberta, e levou como título "Currículo Básico: uma contribuição para a escola pública brasileira". Em 1991, é apresentada a edição do "Currículo Básico: compromisso permanente para a melhoria da qualidade do ensino na escola pública" como proposta de ação no Plano Municipal da Educação, gestão 1989-1992, trazendo consigo a reflexão iniciada anteriormente, mas apresentando alterações próprias de uma nova gestão. Já em 1994, é apresentada uma reformulação do currículo anterior com reorganização dos conteúdos e dos critérios de avaliação. Ainda nessa década, começam a ser gestadas as Diretrizes Curriculares, que apresentarão diferentes versões. Para cada reformulação do currículo, novos cursos foram ofertados aos professores.

Dados coletados na pesquisa de Cartaxo (2009) indicam que em 1990, dos 130 cursos propostos, 36 têm o foco no Currículo Básico: proposta e ação, apresentando especificações para as diferentes áreas do conhecimento. Em 1992, dos 277 cursos realizados, 86 referem-se ao Currículo Básico, sendo que parte dos cursos foram realizados com estudos nas próprias escolas e conduzidos pela sua equipe pedagógica.
Na década de 1990 iniciou-se uma reorganização do trabalho pedagógico na Secretaria de Educação, com a descentralização das ações de apoio técnico e criação do Projeto Alfa. Os núcleos de educação, instalados em regionais do município, passaram a ter os "alfabetizadores de núcleo", responsáveis pelo acompanhamento dos professores alfabetizadores e ficando mais próximo das escolas. Dentre as questões discutidas nesse projeto, encontrase a descontinuidade no encaminhamento metodológico do processo de alfabetização entre a 1aㅡ e a $2^{\underline{a}}$ séries do Ensino Fundamental. A intenção era reavaliar as práticas escolares de exclusão escolar e social e promover uma avaliação de aprendizagem de caráter contínuo e qualitativo.

Data desta década a criação do Parque de Ciências de Curitiba, como polo de produção e socialização de conhecimentos em diferentes áreas, com atividades de formação de professores e atendimento a estudantes do ensino fundamental.

\section{Década de 2000}

Nesta década, manteve-se a estrutura da Semana Pedagógica, reunindo os professores em palestras em diferentes lugares da cidade, devido ao grande número de profissionais que integravam a RME neste período. Durante o ano, eram ofertados cursos nas diferentes áreas do conhecimento e formações nos Núcleos Regionais de Educação. Destacam-se os cursos para professores com foco nos programas de informática e desenvolvimento sustentável (CARTAXO, 2009).

A partir de 2005, os resultados das avaliações em larga escala realizadas pelo Ministério da Educação começam a impactar na formação continuada dos professores no âmbito nacional e municipal. A RME ampara-se nos resultados do índice de Desenvolvimento da Educação Básica (IDEB) para organizar os cursos, visando melhorar a proficiência dos estudantes nas avaliações externas (CARTAXO, 2009; MORAIS, 2009). 
Em 2013, com a mudança de gestão do município, as ações formativas começam a ser repensadas, visto que o Plano Nacional de Educação (PNE) 2014-2024 é aprovado e as discussões sobre a garantia do direito à educação básica com qualidade, equidade e valorização dos profissionais da educação trazem novos desafios para a RME. Nesse período, foram revistos diversos documentos norteadores, como o Plano Municipal de Educação, as Diretrizes Curriculares do Ensino Fundamental, os Projetos Político-Pedagógico das escolas, os Parâmetros e Indicadores de Qualidade, os Regimentos Escolares e o Plano de Carreira dos profissionais do magistério, que reitera a importância da qualificação permanente.

Nesse contexto, no último ano da gestão 2013-2016 reorganiza-se a formação continuada na RME, implementando-se duas ações diferenciadas: a proposta de organização de um Plano de Formação Continuada em cada escola, vinculado ao Plano de Ação institucional, e o Programa de Formação Integrada (PROFI).

Em 2014, a SME propôs às equipes escolares a definição, de forma coletiva, no interior das escolas, do Plano de Formação da escola:

Isso nos leva a pensar de forma mais ampla um plano de formação continuada da escola que consista no planejamento coletivo do processo de formação dos seus profissionais a ser realizado a médio e longo prazo. Ele deve ter como ponto de partida as necessidades da escola, evidenciadas durante o ano letivo por todos os segmentos. Para atender às necessidades, devem ser pensados cursos, estudos, palestras, entre outros, com objetivos que possam contribuir para repensar, reorganizar, resolver os problemas e necessidades identificados no Plano de Ação da Escola. (CURITIBA, 2014 apud MIRA, 2018, p. 182).

Para efetivação desse Plano, foi necessário que a SME divulgasse, no início do ano letivo, todo o cronograma de formações ofertadas, de modo que as escolas tivessem conhecimento prévio dos cursos e pudessem definir coletivamente como organizariam o seu próprio plano de formação. Esse plano deveria considerar a escolha das formações que atendessem às necessidades identificadas, o planejamento de momentos formativos no interior da escola e também os momentos de socialização das formações ao longo do período letivo, envolvendo todos os profissionais da instituição (MIRA, 2018).

Em 2016, o Plano de Formação Continuada divulgado às escolas (CURITIBA, 2016) apresentava mais de 100 eventos de formatos diversos (cursos, seminários, assessoramentos, permanência concentrada, palestras) destinados aos mais de 12 mil professores do ensino fundamental. Nesse contexto, os professores ingressantes na RME, neste período, precisaram de orientação e auxílio, desde o processo de inscrição até a escolha dos cursos, levando em conta a turma assumida, o ano/ciclo de atuação, a escola de lotação (ensino regular ou educação em tempo integral), considerando que suas necessidades formativas eram distintas dos demais profissionais (MIRA, 2018).

Aí, eu falei assim: 'Puxa, para onde eu vou?' Eu não sabia nem como fazer a inscrição! Então, você não tem uma orientação, isso eu senti dificuldade. Sabe, de pegar o 'caminho das pedras': a inscrição, como fazer, essa parte mais burocrática da formação... Mas, como eu estava entrando, eu acho que seria interessante, nesse rol de palestras que tem, fazer alguma coisa direcionada para os que estão começando... Sei lá, uma palestra sobre 'como se apresentar numa sala de aula'... algo nesse sentido, mas para a gente saber como entrar... (PROFESSORA RITA) (MIRA, 2018, p. 182-183).

A questão dos cursos, eu tinha muita dúvida... Que cursos que eu poderia fazer, em que tempo que eu poderia fazer, aonde que eu vou acessar... então, foi um ano que eu tive que ir muito em busca. (PROFESORA ISABEL) (MIRA, 2018, p. 183).

De acordo com Mira (2018), os depoimentos coletados evidenciaram que os professores ingressantes não tiveram orientação suficiente para efetivação desse processo. Além disso, outros professores entrevistados destacaram que, apesar da oferta de uma quantidade signi- 
ficativa de cursos e outros eventos, nem sempre eles atendiam às suas necessidades formativas, inferindo-se que a proposição de uma organização coletiva para o Plano de Formação das escolas enfrentou alguns desafios.

O PROFI foi desenvolvido em 2016. Tinha como público-alvo os docentes dos anos iniciais do Ensino Fundamental e carga horária total de 252 horas. Também foram convidados a participar pedagogos que atuavam nas escolas, considerando que são responsáveis pela organização do trabalho pedagógico e atuam na formação e acompanhamento dos professores no interior dessas instituições. Os encontros aconteciam quinzenalmente, agrupando professores que atuavam em ciclo/anos semelhantes. 0 foco formativo eram os componentes curriculares de Língua Portuguesa e Matemática, definidos com base na análise dos resultados das avaliações externas (Provinha Brasil, Prova Brasil e Avaliação Nacional da Alfabetização (ANA)) (MIRA; GASPARIM, 2017). 0 objetivo geral do PROFI consistia em "propiciar o estudo, a reflexão e o aprimoramento da prática pedagógica na perspectiva de uma formação integrada com os(as) profissionais da educação que trabalham nas escolas de ensino fundamental" (CURITIBA, 2016, p. 11).

0 programa se estruturou como uma formação em rede, buscando a participação colaborativa de todos os profissionais envolvidos: formadores da SME e das regionais, professores e pedagogos das escolas. 0 caderno de orientações do programa ressaltava que a formação foi pensada "com" os profissionais da rede de ensino e não "para" esses profissionais. Nessa perspectiva, o documento indicava: "Faz-se necessário repensar os processos formativos, ampliando a participação colaborativa de todos os sujeitos envolvidos, trazendo os(as) profissionais da educação como protagonistas da ação" (CURITIBA, 2016, p. 9), destacando a importância da formação no coletivo por meio de uma equipe colaborativa em que o aprendizado se efetiva nas relações entre os sujeitos e na investigação da prática dos pro- fessores. Ao assumir a importância das relações entre os sujeitos, altera-se substancialmente a metodologia de formação, que deixa de se sustentar numa relação linear teoria-prática para buscar a construção de relações em que o que um professor vivencia pode auxiliar o outro a resolver seus problemas do cotidiano (GASPARIM, 2019).

Cabia à equipe do nível central realizar a formação das equipes regionais e acompanhar o trabalho realizado com as professoras das escolas. As equipes regionais tinham como principal atribuição a organização dos encontros de formação, partindo das necessidades formativas do grupo de professores atendidos, articulando-os à formação realizada pela equipe central (MIRA; GASPARIM, 2017).

As profissionais selecionadas para atuarem como docentes nesse programa eram pedagogas que já tinham vivência em sala de aula e também experiência como formadoras de professores. Como referência para os processos de formação continuada, foram utilizados os seguintes fundamentos: sujeito epistêmico, aprendizagem colaborativa e trabalho coletivo, provisoriedade do conhecimento, indissociação teoria e prática e homologia dos processos. (MIRA; GASPARIM, 2017, p. 13039).

A homologia dos processos é apresentada como situações formativas desenvolvidas a partir de práticas sociais reais, que contribuam para o professor entender os processos educativos vivenciados pelas crianças: busca-se a coerência entre a didática da formação e a didática adotada para o trabalho docente em sala de aula. Além disso, outro diferencial do Programa foi regionalizar as ações de formação, que aconteciam por núcleo, em escolas próximas ao local de trabalho dos professores, considerando a dificuldade de deslocamento em uma grande cidade (MIRA; GASPARIM, 2017).

A principal ação formativa consistiu na reflexão sobre a prática, na elaboração e análise do planejamento de ensino, considerando os fundamentos do Programa. Além disso, foram utilizadas estratégias visando à unidade e à continuidade entre cada encontro de formação. 
Para tanto, a cada dia de encontro um profissional diferente ficava responsável pelo registro das ações, com o objetivo de documentar o percurso coletivo e rememorar as aprendizagens realizadas. Esse processo também objetivava possibilitar aos formadores acompanhar, ao longo da formação, o progresso dos professores (MIRA; GASPARIM, 2017).

Destaca-se que, além das formações coletivas, foram previstas 292 horas anuais de acompanhamento às unidades escolares pelas formadoras regionais, para assessoramentos in loco visando diagnosticar as necessidades formativas do grupo de professores das escolas, além de avaliar os resultados da formação no planejamento e na prática dos docentes. Esse acompanhamento do trabalho, denominado supervisão, tinha como objetivo instigar as professoras a pensar e (re)elaborar suas práticas, promovendo o trabalho colaborativo e o espírito de investigação, na perspectiva de "criar condições de aprendizagem e desenvolvimento profissionais" (ALARCÃO, 2004, p. 65). 0 depoimento que segue evidenciou a dificuldade em conciliar a carga horária da formação com o acompanhamento nas escolas, considerando-se também outras demandas de trabalho que essas profissionais atendem nas regionais.

É complicado, porque você trabalha com eles, você faz todo esse acompanhamento, mas você não consegue fazer esse acompanhamento in loco. A supervisão, eu acho que a gente ainda precisa caminhar mais...porque a supervisão, a gente ainda não conseguiu achar, de repente, um caminho mais correto, de acompanhar melhor esse professor na escola. Porque o tempo de formação... com o tempo de supervisão, eu acho pouco. Eu acho que a supervisão teria que ser um tempo maior, para poder dar conta de acompanhar realmente esse professor. (BÁRBARA - FORMADORA REGIONAL) (MIRA; GASPARIM, 2017, p. 13045).

Percebe-se que embora conste no documento oficial do PROFI a totalidade de 292 horas anuais de supervisão por regional, essa carga horária - dividida em várias esco- las ao longo do ano - não possibilitou que o acompanhamento ocorresse adequadamente. Observa-se, assim, a existência de fragilidades nesse processo, pois o tempo destinado ao acompanhamento, aliado às condições de trabalho das próprias formadoras, não foi suficiente para um trabalho efetivo nessa direção (MIRA; GASPARIM, 2017).

Considerando as mudanças advindas das eleições municipais em 2016, houve interrupção do desenvolvimento desse Programa no ano seguinte. Nesse sentido, confirma-se uma das críticas sobre a descontinuidade das políticas de formação continuada das redes de ensino, dificultando a consolidação de possíveis avanços oriundos dos processos formativos implementados (GATTI; BARRETO, 2009). Desta forma, os profissionais das escolas ficam reféns dessas mudanças, e vão aprendendo a conviver com elas e a trabalhar nas escolas, apesar delas (MIRA; GASPARIM, 2017).

\section{0 que pensar, então, sobre os processos da formação continuada?}

A caracterização da RME em Curitiba em períodos possibilitou identificar os diferentes movimentos formativos, a fim de identificar a existência de processos de organização coletiva dos/com professores no ensino fundamental a partir das próprias práticas produzidas no contexto de trabalho da escola.

Decorrente das pesquisas consultadas e dos seus resultados, foi possível identificar que na RME de Curitiba ocorreram processos de organização coletiva dos/com os professores, embora de forma descontínua.

Um primeiro movimento de trabalho coletivo, de pequena dimensão, anunciado por Cartaxo (2009), indica iniciativa isolada de um grupo de professores da primeira escola da RME, na década de 1960. Essa organização é caracterizada pelo grupo de professores que decidiram, a partir da necessidade da escola, 
reunir-se aos sábados, voluntariamente, para planejar seu trabalho.

Encontramos em Dalla-Bona (1990), Cartaxo (2009) e Vieira (2010) análises que indicam o final da década de 1980 como um período em que começa a ser gestado um movimento de mudança decorrente do movimento nacional pós-ditadura, evidenciando-se a dimensão política do ato pedagógico. A década de 1990 se constitui como um período marcado pela forte participação coletiva dos professores e formas de organização do trabalho no interior das escolas, os olhares voltam-se para as questões da prática e a problemática do ensino recai sobre o processo de produção e sistematização coletiva do conhecimento, passando o aluno a ser visto como sujeito portador de uma prática social e com interesses próprios.

Essa forma de organização que considera as necessidades de seus profissionais vai ao encontro da ideia de Veiga (1995), quando afirma que a formação continuada deve se centrar na escola e fazer parte do projeto político-pedagógico, sendo de sua competência fazer o levantamento das necessidades e elaborar um programa de formação continuada, com apoio dos órgãos centrais.

Neste mesmo sentido, as pesquisas de Mira e Gasparim (2017) e Gasparin (2019) indicam que o PROFI, desenvolvido em 2016, se constituiu como uma ação de duração mais extensa, realizada ao longo do ano, diferenciando-se dos cursos rápidos ofertados anteriormente. Destacam-se, nesta formação, aspectos como a regionalização, o trabalho com grupos menores de participantes, o investimento na formação das formadoras e a participação do pedagogo escolar junto aos professores no Programa. Em relação às ações formativas e suas implicações, destaca-se a estratégia de ampliação cultural e a possibilidade de realização de trocas de experiências entre os participantes com reflexão sobre a prática, aliado a momentos de elaboração de planejamento(s) que permitiram estabelecer relações entre os conteúdos trabalhados na formação e a prática docente cotidiana.
No contexto dos movimentos de formação continuada identificamos alguns aspectos que podem ser considerados elementos determinantes na direção de fragilizar a organização coletiva dos docentes: a ausência de um projeto de formação, a influência das avaliações em larga escala e a perspectiva da distribuição do conhecimento.

A ausência de um projeto de formação é evidenciada na pesquisa de Morais (2009), indicando que a formação continuada na RME de Curitiba foi marcada pela tendência ao desenvolvimento de uma técnica de trabalho, muito mais do que a discussão sobre ela. Destaca a tendência de retorno ao treinamento, com propostas de oficinas e elaboração de manuais para os professores, e a ausência de um programa de formação continuada para orientar o trabalho dos professores sob uma única diretriz teórico-metodológica.

Essa descontinuidade é destacada nas pesquisas de Mira (2018) e Gasparim (2019). A proposição da organização de um Plano de Formação Continuada pelas escolas, iniciada em 2014, não teve continuidade. Como um dos limites do PROFI, Gasparim (2019) pondera que a formação analisada foi organizada em determinado contexto histórico e político, e que isso tem implicações para o "fazer" de formadores e professores. As mudanças ocorridas na gestão da SME, em razão das eleições municipais, provocaram a descontinuidade do Programa. Em decorrência, verifica-se a inexistência de uma política de formação continuada para além dos limites de uma gestão municipal, evidenciando a fragilidade das ações formativas organizadas pelos municípios, as quais ficam na dependência da decisão dos grupos que ocupam os cargos de liderança em cada gestão. De acordo com Gatti e Barreto (2009), a formação continuada conduzida com exclusividade pelos sistemas de ensino fica ao sabor das descontinuidades administrativas, com todos os efeitos negativos decorrentes. Infelizmente, o caso analisado não se constituiu uma exceção. 
A partir de 2000, observa-se um movimento caracterizado pela intensificação da aprendizagem com o objetivo de "aprender a aprender", em que as habilidades específicas são conceituadas como competências previamente definidas nos programas de aprendizagem. O contexto das avaliações em larga escala determina as formações dos professores voltada para a busca de resultados, no sentido de melhoria das pontuações na escala de proficiência e de aumento do IDEB.

Mira (2018) apresenta evidências da relação entre a formação continuada e os resultados das avaliações externas, mostrando a pressão que as escolas e seus profissionais vivem em relação ao desempenho dos estudantes nessas provas. Essa pressão por resultados refere-se ao que Candau (2013) denomina de cultura da performatividade, cuja lógica penetra nas escolas, instrumentalizando os processos de formação continuada e impactando na própria subjetividade dos docentes, os quais são muitas vezes responsabilizados pelos resultados obtidos.

Análise de Cartaxo, Romanowski e Martins (2016) aponta que a formação dos professores da RME de Curitiba tem seguido um caminho de monitoramento do ensino e da aprendizagem, a partir de algumas ações de organização e delimitação dos conteúdos e critérios, a realização de provas padronizadas para todas as escolas e seminários para discussão dos resultados.

Contraditoriamente, ainda que os estudos sobre o desenvolvimento profissional apontem a análise da aprendizagem dos estudantes como um eixo articulador e um princípio desse processo (VAILLANT; MARCELO, 2012), sua vinculação aos resultados da aprendizagem em termos do desempenho discente nas avaliações externas, embora possa contribuir para alavancar o desenvolvimento docente, também produz um sentimento de pressão vinculado à produtividade.

As críticas feitas pelos professores confirmam - junto à valorização da formação continuada - a necessidade de rever a concepção e a forma como esses processos vêm sendo efetivados. Essas críticas se referem a uma concepção de formação pautada na distribuição do conhecimento que desvincula teoria e prática: tanto nos casos de formações que privilegiam a prática (receitas prontas) em detrimento da reflexão teórica que contribuiria para a análise dessa prática, quanto em formações que se distanciam da realidade das escolas e das necessidades formativas dos docentes. Superar essa concepção prescritiva da formação docente constitui uma questão fundamental, que se aproxima das reflexões realizadas por Romanowski e Martins (2013, p. 13):

A partir da prática, as situações e dificuldades examinadas e refletidas permitem ao professor buscar explicações dos determinantes que a condicionam. Ao buscar explicações o processo de formação é favorecido, o professor compreende sua própria prática, ou seja, teoriza sobre sua prática.

A partir dessa análise é possível verificar um movimento de crítica às formações descontextualizadas, que não estabelecem relação entre teoria e prática, assentadas numa perspectiva verticalizada, transmissiva. Considerar a escola como espaço de formação implica não apenas tê-la como lócus formativo, mas, de fato, tomar como ponto de partida as demandas da prática apresentadas pelos professores para que a formação seja efetiva, no sentido de aprendizagens relevantes para a docência e também para os estudantes.

\section{Concluindo...}

Após caracterizar os diferentes movimentos formativos e a ausência de um projeto de formação que considere os processos de organização coletiva dos/com professores no ensino fundamental a partir das próprias práticas produzidas no contexto de trabalho da escola, reforçamos nossa visão do professor como sujeito. Isso implica dar voz a ele, implica sua participação efetiva nas decisões a respeito dos processos formativos de que 
ele é participante, para que possam estar voltados ao atendimento de suas necessidades de formação. Isso significa o professor assumir o papel de sujeito produtor de conhecimentos, possibilitando reconstruir os sentidos da docência nos seus discursos e nas práticas realizadas. Esses processos possibilitam ao professor distanciar-se de uma formação tutelada por agentes externos, empreendendo um esforço de autodeterminação ao construir sua própria formação, o que contribuiria para sua emancipação intelectual (THOMPSON, 1988). Na ausência desses fatores, essas formações podem trazer poucas contribuições ao desenvolvimento profissional dos docentes.

Considerando o exposto, defende-se a necessidade de mudanças mais profundas, relacionadas à concepção de formação continuada ainda vigente: de uma formação voltada à distribuição dos conhecimentos para processos formativos fundamentados na concepção da teoria como expressão da prática (MARTINS, 1998). Isso implica em processos formativos concebidos numa perspectiva reflexiva e colaborativa, que tem como ponto de partida os problemas reais da prática docente, em oposição a uma lógica prescritiva e aplicacionista da relação teoria-prática.

Nesse contexto, revelam-se fundamentais as ações realizadas no interior das escolas, organizadas e mantidas pelas iniciativas de professores e equipes pedagógicas, na direção de formações pautadas no trabalho coletivo, em grupos de apoio entre docentes e escolas, ações que muitas vezes conseguem sobreviver às mudanças políticas, porque têm como princípio de organização a autonomia - sempre relativa - dos sujeitos no movimento de construção de sua história.

\section{REFERÊNCIAS}

ALARCÃO, I. Professores reflexivos numa escola reflexiva. 3. ed. São Paulo: Cortez. 2004.

BRASIL. Presidência da República. Casa Civil. Lei no 5.692, de 11 de agosto de 1971. Brasília, DF, 1971.
Disponível em: http://.planalto.gov.br/ccivil_03/ Leis/L5692.htm. Acesso em: 06 dez. 2019.

CANDAU, V. M. Currículo, didática e formação de professores: uma teia de ideias-força e perspectivas de futuro. In: OLIVEIRA, M. R. N. S.; PACHECO, J. A. (org.) Currículo, didática e formação de professores. Campinas, SP: Papirus, 2013. p. 7-20.

CARTAXO, S. R. M. Formação continuada do professor alfabetizador: abordagens, processos e práticas. 2009. 148 f. Dissertação (Mestrado em Educação) - Pontifícia Universidade Católica do Paraná (PUC/PR), Curitiba, 2009.

CARTAXO, S. R. M.; ROMANOWSKI, J. P.; MARTINS, P. L. O. Tensões e prioridades no processo de formação continuada do alfabetizador: da concepção à prática de formação. Práxis Educativa, Ponta Grossa, PR, v. 11, n. 3, set./dez. 2016. Disponível em: http://www. revistas2.uepg.br/index.php/praxiseducativa. Acesso em: 06 dez. 2019.

COSTA, V. A. A. Memória da rede municipal de ensino de Curitiba (1963-1982). Boletim da Casa Romário Martins, Curitiba, v. 30, n. 133, mar. 2007.

CURITIBA. Política de Educação para uma Escola Aberta, 1983-1986. Curitiba: Secretaria Municipal de Educação, 1984.

CURITIBA. Memórias da rede municipal de ensino de Curitiba (1963-1982). Boletim Casa Romário Martins, Curitiba, v. 30, n. 133, mar. 2007.

CURITIBA. Secretaria Municipal de Educação. Programa de Formação Integrada (PROFI). Curitiba, 2016.

DALLA-BONA, E. M. As propostas de treinamento e aperfeiçoamento de professores na rede municipal de ensino de Curitiba - uma análise crítica e uma solução: o assessoramento. 1990. 205 f. Dissertação (Mestrado em Educação) Universidade Federal do Paraná (UFPR), Curitiba, 1990.

DINIZ-PEREIRA, J. E. Desenvolvimento profissional docente: um conceito em disputa. In: IMBERNÓN, F; SHIGUNOV NETO, A.; FORTUNATO, I. (org.). Formação permanente de professores: experiências iberoamericanas. São Paulo: Hipótese, 2019. p. 65-74.

FRANCO, M. A. S. Formação continuada de/ para/com docentes: para quê? Para quem? In: IMBERNÓN, F; SHIGUNOV NETO, A.; FORTUNATO, I. (org.). Formação permanente de professores: experiências iberoamericanas. São Paulo: Hipótese, 
2019. p. 96-109.

GASPARIM, R.; Programa de formação integrada: PROFI e as contribuições para a prática pedagógica na educação básica. 2019. 107 f. Dissertação (Mestrado em Educação) - Pontifícia Universidade Católica do Paraná (PUC/PR), Curitiba, 2019.

GATTI, B. A.; BARRETO, E. S. S. (coord.). Professores do Brasil: impasses e desafios. Brasília, DF: UNESCO, 2009.

IMBERNÓN, F. Formação docente e profissional: formar-se para a mudança e a incerteza. São Paulo: Cortez, 2002. (Coleção Questões da nossa época, v. 77).

MARTINS, P. L. O. A relação conteúdo-forma: expressão das contradições da prática pedagógica na escola capitalista. In: VEIGA, Ilma Passos Alencastro (org.). Didática: o ensino e suas relações. Campinas, SP: Papirus, 1996. p. 77-103.

MARTINS, P. L. O. A didática e as contradições da prática. Campinas, SP: Papirus, 1998.

MIRA, M. M. Inserção profissional docente: sistematização de princípios e indicadores para a melhoria do processo. 2018.246f. Tese (Doutorado em Educação) - Pontifícia Universidade Católica do Paraná (PUC/PR), Curitiba, 2018.

MIRA, M. M.; GASPARIM, R. Limites e contribuições de um programa de formação continuada. In: EDUCERE - CONGRESSO NACIONAL DE EDUCAÇÃO, 11, 2017, Curitiba. Anais [...] Curitiba: Pontifícia Universidade Católica do Paraná, 2017. p. 13033-
13048. Disponível em: https://educere.bruc.com. br/arquivo/pdf2017/23509_11734.pdf. Acesso em: 30 nov. 2019.

MORAIS, M. C. F. Z. B. de. Os caminhos da formação continuada na rede municipal de ensino de Curitiba. 2009. 241 f. Dissertação (Mestrado em Educação) - Universidade Federal do Paraná (UFPR), Curitiba, 2009.

ROMANOWSKI, J. P.; MARTINS, P. L. O. Desafios da formação de professores iniciantes. Páginas de Educación, Montevideo, v. 6, n. 1, p. 8396, jun. 2013. Disponível em: http://www.scielo. edu.uy/scielo.php?script=sci_arttext\&pid=S1688$74682013000100005 \& \operatorname{lng}=e s \& n r m=i s o$. Acesso em: 06 dez. 2019.

THOMPSON, E. P. A formação da classe operária inglesa: a maldição de Adão. 2. ed. Vol. II. Rio de Janeiro: Paz e Terra, 1988.

VAILLANT, D.; MARCELO, C. Ensinando a ensinar: as quatro etapas de uma aprendizagem. Curitiba: EdUTFPR, 2012.

VEIGA, I. P. A. (org.). Projeto político-pedagógico da escola. Campinas, SP: Papirus, 1995. (Coleção Magistério: formação e trabalho pedagógico).

VIEIRA, A. M. D. Caminhos e descaminhos na formação continuada de professores: as políticas públicas da Rede Municipal de Ensino de Curitiba (1963-1996). 2010. 341 f. Tese (Doutorado em Educação) - Pontifícia Universidade Católica do Paraná, Curitiba, 2010.

Recebido em: 15/12/2019

Aprovado em: 03/02/2020 